Check for updates

Cite this: J. Mater. Chem. C, 2020 8,3740

Received 23rd September 2019, Accepted 2nd January 2020

DOI: $10.1039 / c 9 t c 05228 c$

rsc.li/materials-c

\title{
On the importance of pyrolysis for inkjet-printed oxide piezoelectric thin films $\dagger$
}

\author{
Nicolas Godard, (D) * Mohamed Aymen Mahjoub, (D) Stéphanie Girod, \\ Tony Schenk, (D) Sebastjan Glinšek (D) and Emmanuel Defay (D)
}

\begin{abstract}
Inkjet printing (IJP) is an attractive technology for the low-cost fabrication of functional metal oxide thin films, such as piezoelectric lead zirconate titanate (PZT). Implementation of the well-established chemical solution deposition method for PZT films in the IJP process comes with challenges, which were the focus of several works in the field. However, adequate pyrolysis conditions are also required for the complete elimination of organic residues from the layers before crystallization. Thanks to an original technique based on infra-red spectroscopy, the present study draws the correlation between the amount of residual organics in pyrolyzed inkjet-printed layers on platinized silicon and the porosity and functional properties of the final films. Pyrolysis at $475{ }^{\circ} \mathrm{C}$ for $3 \mathrm{~min}$ afforded dense $\{111\}$-textured $200 \mathrm{~nm}$-thick PZT layers after crystallization at $700{ }^{\circ} \mathrm{C}$, with state-of-the-art electrical properties $\left(P_{\mathrm{r}}=23 \mu \mathrm{C} \mathrm{cm}^{-2}, E_{\mathrm{C}}=60 \mathrm{kV} \mathrm{cm}{ }^{-1}, \varepsilon^{\prime}=1000\right.$ and $\left.\tan \delta=0.04\right)$. Potential of inkjet printing technology for piezoelectric devices is demonstrated through a simple energy harvesting device, with a $5.8 \mu \mathrm{W}$ power output for a $6 \mathrm{k} \Omega$ resistive load.
\end{abstract}

\section{Introduction}

Lead zirconate titanate $\left(\mathrm{Pb}(\mathrm{Zr}, \mathrm{Ti}) \mathrm{O}_{3}, \mathrm{PZT}\right)$ thin films are a common choice for the fabrication of piezoelectric devices ranging from microelectromechanical systems (MEMS) to energy harvesters. ${ }^{1-3}$ The concept of energy harvesting $(\mathrm{EH})$ is based on the conversion of mechanical energy present in the environment in the form of low-frequency vibrations (buildings, vehicles, infrastructure etc.) into electrical energy that can be used to power small devices, such as autonomous sensors. ${ }^{4}$ The success of these piezoelectric devices is in line with the mastery of chemical solution deposition (CSD) as a low-cost method with respect to physical vapor deposition (PVD) techniques for the fabrication of high-quality films ${ }^{5}$ and opens up opportunities for mass production.

As the name implies, CSD is based on the deposition on a substrate of a solution containing precursors of the functional metal oxide. This deposition is conventionally performed via spin or dip coating and is followed by a series of thermal steps to successively eliminate the solvent(s) (drying) and the residual organic content (pyrolysis and thermolysis) before converting the amorphous metal oxide into the desired crystalline phase (crystallization). ${ }^{6,7}$

Fabrication costs of piezoelectric thin films can further be decreased by combining CSD with an additive manufacturing

Materials Research and Technology Department, Luxembourg Institute of Science and Technology, rue du Brill 41, L-4422 Belvaux, Luxembourg.

E-mail: nicolas.godard@list.lu; Tel: +352 275885

$\dagger$ Electronic supplementary information (ESI) available. See DOI: 10.1039/c9tc05228c technique such as inkjet printing (IJP), where the precursor solution is deposited at precise locations onto the substrate in the form of small individual droplets $\left(V_{\text {droplet }}=1-100 \mathrm{pL}\right){ }^{8}$ This drastically reduces material consumption with respect to conventional deposition methods and alleviates the need for cost-intensive lithography and etching steps in the case of patterned layers. The typical feature size achievable by IJP can range from $10 \mu \mathrm{m}$ to several $\mathrm{cm}$, the latter being of particular interest for EH devices. The development and implementation of inkjet printing steps in the manufacture of piezoelectric energy harvesters has therefore potential benefits from an economic standpoint, if compared with conventional CSD or PVD processes.

Early reports on inkjet printing of PZT in 1999 focused on jetting of aqueous dispersions of PZT powders. ${ }^{9}$ In 2005, Wang and Derby used paraffin dispersions of PZT powders to print cm-sized ceramic objects. ${ }^{10}$ More recently, another group also reported on powder-based formulations for the deposition of thick films. ${ }^{11,12}$ However, these processes afford porous materials and the high sintering temperatures are unsuitable for the fabrication of PZT thin films on silicon substrates.

Following the seminal work of Bathurst et al. ${ }^{13}$ CSD-based inkjet printing of PZT thin films was described in a number of publications. ${ }^{14-16}$ These works shed light upon the challenges related to inkjet printing. Indeed, several requirements need to be fulfilled for successful implementation of CSD in the IJP process. First, the rheological properties have to be adjusted to enable droplet formation. The dimensionless parameter $Z$ related to the Reynolds (Re) and Weber (We) numbers is usually 
associated with this ability and describes the balance between surface tension and viscous forces of the ink. ${ }^{17}$ It is expressed as follows:

$$
Z=\frac{\mathrm{Re}}{\sqrt{\mathrm{We}}}=\frac{\sqrt{a \gamma \rho}}{\eta}
$$

where $a$ is the characteristic length (nozzle size), $\gamma$ is surface tension, $\rho$ is density and $\eta$ is viscosity. High $Z$ values, associated with low viscosity, result in the formation of undesired satellite droplets, while low $Z$ values can render jetting impossible due to high viscosity. Adequate $Z$ values are in the range 1-10, according to Jang et al. ${ }^{17}$ Two additional constraints related to the energy of the droplet set the limits of the printable range: it needs to be sufficient to overcome the interfacial tension at the nozzle during droplet formation (We $>4$ ), but low enough to prevent fragmentation into smaller droplets (splashing) upon impact with the substrate $\left(\mathrm{We}^{1 / 2} \mathrm{Re}^{1 / 4}<50\right) .{ }^{8}$ Standard CSD precursors of PZT based on the 2-methoxyethanol (MOE) route ${ }^{6}$ are characterized by low viscosity and can hardly be used in IJP as such. Nozzle clogging may also arise if the solvent is too volatile at the printhead operating temperature. This may require frequent purging, resulting in high ink consumption and decrease of the printhead lifetime. The adjunction of highboiling-point co-solvents, such as glycerol and ethylene glycol, increases solution viscosity, which strongly improves jetting stability and helps prevent nozzle clogging. ${ }^{15}$

In addition, it was shown that such a ternary solvent system also serves a purpose related to the ink drying behavior. The coffee ring effect refers to capillary flow-driven transport of material to the edge of a drying liquid film as the solvent evaporates. ${ }^{18}$ This effect is not desirable in printed film structures and can be counteracted by the presence of high-boiling-point co-solvents which redistribute the solute through an inward Marangoni flow. ${ }^{19,20}$

Control of surface wetting is also a crucial parameter. Highsurface-energy substrates such as platinized silicon are affected by extreme ink spreading and therefore poor resolution (see Fig. S1, ESI $\dagger$ ). Typical solutions to this issue are represented by surface modification with polymeric layers ${ }^{21}$ or self-assembled monolayers. ${ }^{15}$ Precise control of surface wettability can enable lithography-free printing resolution in the sub-100 $\mathrm{nm}$ range. ${ }^{22}$

Finally, it follows that modifications in the solution composition may bring about adaptations in the thermal post-printing steps. Similarly to conventional CSD processing, pyrolyzed layers should consist of metal oxide free from organic residues. Usually this decomposition is thermally induced by heating the dried film at $\sim 350{ }^{\circ} \mathrm{C}$ (lower than the crystallization temperature), ${ }^{7}$ but it can also be assisted by photochemical ${ }^{23}$ or combustion-based ${ }^{24}$ processes. We previously reported on inkjet-printed PZT thin films. ${ }^{15}$ Although encouraging when compared to similar works on inkjet printing, ${ }^{13,14,16}$ the electromechanical properties of our layers were inferior to state-of-the-art CSD-derived films, which could be ascribed to porosity originating from incomplete elimination of the high-boiling-point solvents during pyrolysis. This issue was not thoroughly addressed in previous works.

In this work, we report an investigation of the influence of pyrolysis conditions on the microstructure and properties of inkjet-printed PZT thin films. In particular, we correlate the amount of residual organics in the films after the pyrolysis stage with the porosity and properties of the final films crystallized at $700{ }^{\circ} \mathrm{C}$. We show that it is possible to fabricate dense films with $\{111\}$ preferential orientation and state-of-the-art electrical properties via inkjet printing. Finally, potential applications of these layers are exemplified by simple energy harvesters based on inkjet-printed PZT films.

\section{Experimental procedures}

\subsection{Preparation and characterization of PZT precursor solutions}

The PZT spin coating solution and the PZT ink were prepared based on the procedure described in Godard et al. ${ }^{15}$ Freezedried lead(II) acetate, zirconium(IV) butoxide and titanium(Iv) isopropoxide were used as metal precursors. The stoichiometry of metal cations was such that $\mathrm{Pb}: \mathrm{Zr}: \mathrm{Ti}=1.10: 0.53: 0.47$ (morphotropic phase boundary composition with $10 \% \mathrm{~Pb}$ excess). Acetylacetone ( $2 \mathrm{~mol}$ equiv.) was added to modify the $\mathrm{Zr}$ and Ti alkoxide precursors. After dissolution in 2-methoxyethanol, the mixture was refluxed under inert atmosphere and gentle stirring for $2 \mathrm{~h}$. The solution was subsequently distilled and diluted with 2-methoxyethanol such that $C_{\mathrm{Zr}}+C_{\mathrm{Ti}}=0.3 \mathrm{~mol} \mathrm{~L}^{-1}$ (PZT spin coating solution). Finally, $2.3 \mathrm{~mL}$ of glycerol and $0.9 \mathrm{~mL}$ of ethylene glycol were added to $6.7 \mathrm{~mL}$ of this solution to obtain the $0.2 \mathrm{~mol} \mathrm{~L}^{-1}$ PZT ink.

Viscosity of the solutions was evaluated via the parallel plate method (plate diameter $50 \mathrm{~mm}$ and gap $1 \mathrm{~mm}$ ) using an MCR 502 rheometer (Anton Paar, Austria), for a shear rate of $100 \mathrm{~s}^{-1}$ (steel cup filled with $2 \mathrm{~mL}$ of ink). The flow curves are presented in Fig. S2 (ESI $\dagger)$. Surface tension was determined using the pendant drop method. Pictures of $4 \mu \mathrm{L}$ droplets hanging from $0.51 \mathrm{~mm}$-diameter needles were recorded using an OCA 25 goniometer (DataPhysics, Germany) and processed using the free software OpenDrop. ${ }^{25}$ Thermogravimetric and differential thermal analyses of the solutions were carried out using an STA 409 PC thermal analyzer (Netzsch, Germany), with a heating rate of $10{ }^{\circ} \mathrm{C} \min ^{-1}$ under air atmosphere.

\subsection{Printing and annealing process}

The PZT ink was injected into a Dimatix DMCLCP-11610 cartridge (10 pL nominal drop volume, Fujifilm, Japan) through a $0.2 \mu \mathrm{m}$ PTFE filter. The cartridge was mounted onto the printhead of a Ceradrop X-Serie (MGI Group, France) inkjet printer. The printhead temperature was set to $30{ }^{\circ} \mathrm{C}$ for optimal jetting. The jetting waveform is shown in Fig. S3 (ESI $\dagger$ ). Platinized silicon wafers (sputtered Pt [100 nm]/sputtered and oxidized Ti [20 nm]/thermal $\mathrm{SiO}_{2}[500 \mathrm{~nm}] / \mathrm{Si}$ ) were cut into $3 \times 1.5 \mathrm{~cm}^{2}$ substrates, which were degassed on a hot plate at $350{ }^{\circ} \mathrm{C}$ for 5 min before printing.

All 16 nozzles of a DMCLCP-11610 cartridge (10 pL nominal volume) were used for printing three $25 \times 4 \mathrm{~mm}^{2}$ rectangles with PZT ink. The droplet spacing along the $x$ and $y$-axes was $15 \mu \mathrm{m}$ and $254 \mu \mathrm{m}$ (spacing between consecutive nozzles), respectively. This printing strategy has the advantage of depositing small volumes of ink per unit area on the substrate $\left(\sim 3 \mathrm{~nL} \mathrm{~mm}^{-2}\right)$, 
thus limiting lateral spreading of the ink despite the strong wetting (see Fig. S1, ESI $\dagger$ ). No prior surface modification of the platinized silicon substrate was therefore performed. A profilometry measurement of the final crystallized film is shown in Fig. S4 (ESI $\dagger$ ). The jetting frequency was $4 \mathrm{kHz}$ and the printhead was kept $0.8 \mathrm{~mm}$ above the substrate. After printing, the wet film was dried at $175{ }^{\circ} \mathrm{C}$ for $1 \mathrm{~min}$ and pyrolyzed at temperatures ranging from 350 to $475{ }^{\circ} \mathrm{C}$ for $3 \mathrm{~min}$. The next layer was printed on top of the previous one in the same conditions. After pyrolysis of the 12th layer, the film was crystallized in air at $700{ }^{\circ} \mathrm{C}$ for $5 \mathrm{~min}\left(50{ }^{\circ} \mathrm{C} \mathrm{s}^{-1}\right)$, which afforded a 200 nm-thick PZT film.

\subsection{Characterization details}

Fourier transform infra-red (FTIR) spectra were acquired on a Bruker Vertex 70 spectrometer (Bruker, USA). The PZT ink was analyzed in attenuated total reflectance (ATR) mode, while the dried, pyrolyzed and crystallized PZT films were characterized using a grazing angle objective (GAO). Spectra were processed with the software OPUS (average over 3 measurements for each condition). X-ray diffraction (XRD) patterns were recorded on a Bruker D8 diffractometer (Bruker, USA) in $\theta-2 \theta$ configuration using $\mathrm{Cu}-\mathrm{K}_{\alpha}$ radiation. X-ray reflectivity (XRR) patterns were recorded using a PANalytical X'Pert Pro diffractometer (PANalytical, Netherlands) with $\mathrm{Cu}-\mathrm{K}_{\alpha}$ radiation. Investigation of the microstructure was performed with a Helios NanoLab 650 (FEI, USA) scanning electron microscope (SEM). Sputtered $100 \mu \mathrm{m}$ diameter platinum top electrodes were patterned by lift-off photolithography. The electrodes were annealed at $400{ }^{\circ} \mathrm{C}$ for $10 \mathrm{~min}$ before electrical characterization to improve the interface between Pt and PZT. Ferroelectric and dielectric measurements were carried out using a TF Analyzer 2000 (aixACCT, Germany). Large-signal measurements of polarization-electric field loops were carried out at $100 \mathrm{~Hz}$ up to $\pm 500 \mathrm{kV} \mathrm{cm}^{-1}$, while small-signal measurements of permittivity-electric field loops were carried out at $1 \mathrm{kHz}$ with a small-signal amplitude of $100 \mathrm{mV}$, up to DC bias fields of $\pm 500 \mathrm{kV} \mathrm{cm}^{-1}$. For each sample, electrical measurements were carried out on 5 different electrodes. The reported values are averages over these 5 measurements.

\subsection{Fabrication and characterization of energy harvesters}

The fabrication of energy harvesters is based on the inkjet printing procedure described above. A single energy harvesting device consists of a $6 \times 1 \mathrm{~cm}^{2}$ platinized silicon beam on which two $20 \times 4 \mathrm{~mm}^{2}$ PZT rectangles were printed, $1 \mathrm{~cm}$ away from the edge (clamping area). The PZT films were pyrolyzed at $425{ }^{\circ} \mathrm{C}$ for $3 \mathrm{~min}$. Five deposition cycles were performed to obtain $1 \mu \mathrm{m}$-thick PZT films. Sputtered $18.692 \mathrm{~mm} \times 2.675 \mathrm{~mm}=$ $50 \mathrm{~mm}^{2}$ platinum top electrodes were patterned by lift-off photolithography on each of the PZT rectangles. A $3.0 \mathrm{~g}$ proof mass ( $0.02 €$ coin) was attached to the extremity using a hot-melt adhesive. After poling ( $\left.200 \mathrm{kV} \mathrm{cm}^{-1}, 10 \mathrm{~min}, 150{ }^{\circ} \mathrm{C}\right)$, the energy harvesters were tested using a dedicated setup (see Fig. 6a) based on a subwoofer (Pioneer TS-SW2002D2) equipped with a platform and a clamping system. A sine signal from a function generator (Agilent 33210A) amplified by a Pioneer GM-D8601 amplifier was used to drive the subwoofer. The output root mean square (RMS) voltage $V_{\mathrm{RMS}}$ was measured with an oscilloscope (Tektronix TDS2004C) across a variable resistive load $R$ connected in parallel with the sample terminals. The output power was calculated as follows: $P=V_{\mathrm{RMS}}{ }^{2} / R$.

\section{Results \& discussion}

\subsection{Ink characterization}

The ink formulation was described in a previous work. ${ }^{15}$ The physicochemical properties of a standard PZT spin coating solution and the PZT ink are presented in Table 1 . The $Z$ number was calculated using eqn (1) for a $10 \mathrm{pL}$ nominal volume Fujifilm Dimatix DMP-11610 cartridge, whose nozzles are $21 \mu \mathrm{m}$-sided square channels. The spin coating solution has a $Z$-value of 13.4 , while that of the ink was decreased down to 3.5 thanks to the addition of glycerol and ethylene glycol, bringing it into the jettable range, as shown in Fig. 1a. It has to be noted that these $Z$-values were evaluated for room temperature. In typical printing conditions, the printhead temperature is higher $\left(T_{\text {printhead }}=30^{\circ} \mathrm{C}\right)$. Although $Z$ is expected to increase with temperature as a consequence of lower viscosity, ${ }^{17}$ it is assumed to stay within the jettable zone, as demonstrated by the excellent jetting quality of our PZT ink formulation across a wide frequency range as shown in the stroboscopic image of Fig. 1b. Since slight deviations in droplet velocity could be observed at the highest jetting frequencies (10 kHz), $4 \mathrm{kHz}$ was selected in this study as compromise between printing time and jetting stability.

Thermogravimetric analysis (TGA) coupled with differential thermal analysis (DTA) of the PZT spin coating solution and PZT ink is presented in Fig. 2. For the spin coating solution, drying is marked by a significant loss of mass and endothermic peak centered at $\sim 140{ }^{\circ} \mathrm{C}$, corresponding to the evaporation of 2-methoxyethanol. In the case of the PZT ink, it is clear that the drying step is shifted towards higher temperatures. The initial loss of mass is associated with two endothermic events centered at $\sim 155{ }^{\circ} \mathrm{C}$ and $\sim 275{ }^{\circ} \mathrm{C}$, which can be associated with the evaporation of 2-methoxyethanol and ethylene glycol up to $200{ }^{\circ} \mathrm{C}$ and the evaporation of glycerol between 250 and $300{ }^{\circ} \mathrm{C}$, respectively. Decomposition of glycerol could also take place at temperatures below $300{ }^{\circ} \mathrm{C},{ }^{26}$ but the absence of a clear exothermic signature in the DTA signal suggests that its elimination from the system is mainly dominated by evaporation in this temperature range. The formation of azeotropic mixtures in this ternary solvent

Table 1 Room-temperature physicochemical properties of the PZT spin coating (SC) solution and the PZT ink prepared from it by adjunction of glycerol and ethylene glycol. $Z$ was calculated for a nozzle size of $21 \mu \mathrm{m}$. Concentration is defined as $C_{Z r}+C_{T i}$ in the solution

\begin{tabular}{lcc}
\hline & PZT SC solution & PZT ink \\
\hline Concentration $\left(\mathrm{mol} \mathrm{L}^{-1}\right)$ & 0.3 & 0.2 \\
Surface tension $\left(\mathrm{m} \mathrm{N} \mathrm{m}^{-1}\right)$ & 32.5 & 34.2 \\
Density $\left(\mathrm{g} \mathrm{cm}^{-3}\right)$ & 1.05 & 1.11 \\
Viscosity $(\mathrm{mPa} \mathrm{s})$ & 2.0 & 8.1 \\
$Z$ & 13.4 & 3.5
\end{tabular}



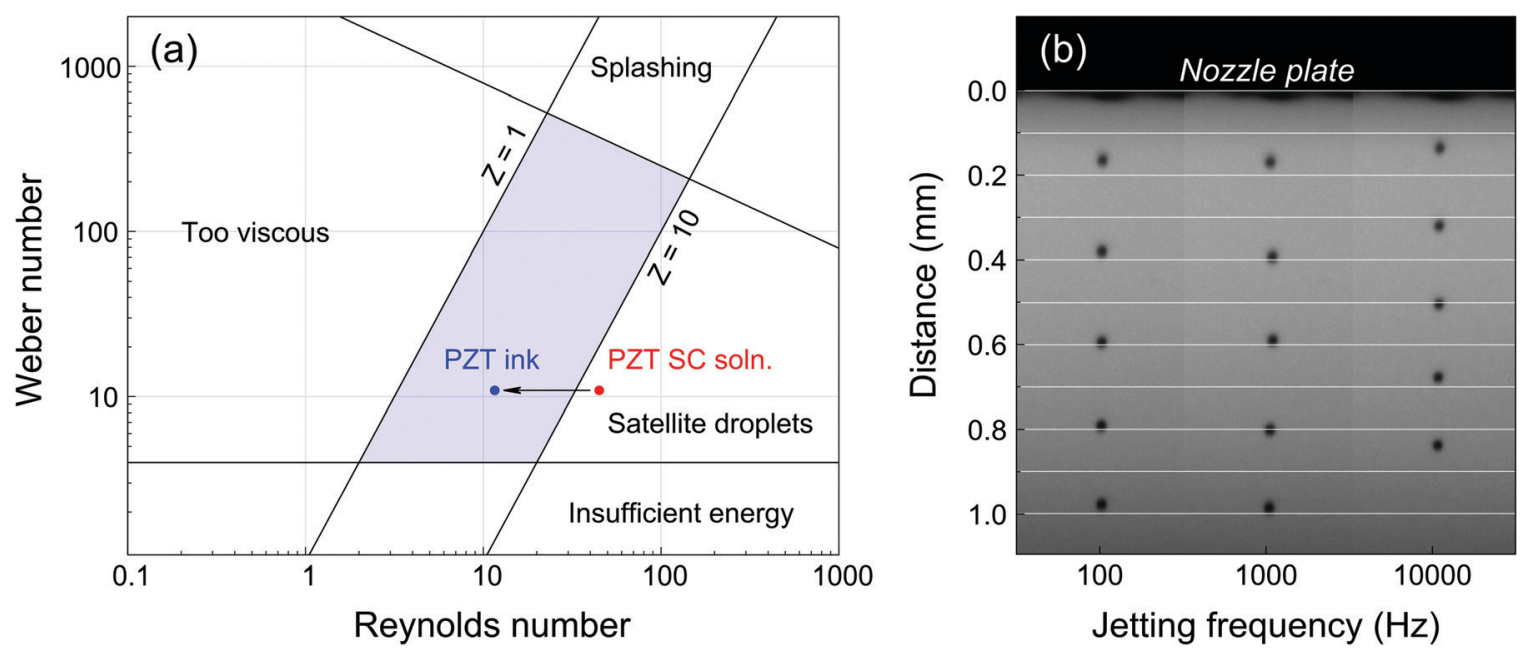

Fig. 1 (a) Representation of the jettable range in terms of Weber and Reynolds numbers (adapted from Derby ${ }^{8}$ ) and effect of solvent modification on the jettability of PZT CSD precursor solutions. (b) Stroboscopic picture of PZT ink ejected using a DMC-11610 cartridge (50 $\mu$ s pitch). Droplets ejected at $100 \mathrm{~Hz}$ and $1 \mathrm{kHz}$ travel at $\sim 4 \mathrm{~m} \mathrm{~s}^{-1}$, while droplets ejected at $10 \mathrm{kHz}$ travel close to $3.5 \mathrm{~m} \mathrm{~s}^{-1}$.

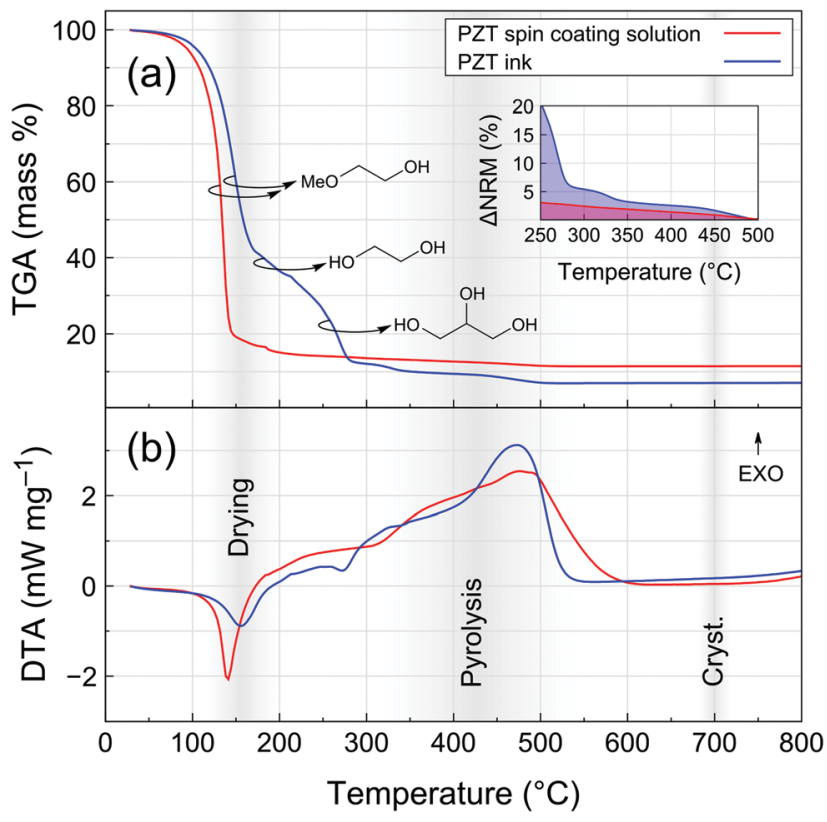

Fig. 2 (a) Thermogravimetric analysis (TGA) coupled with (b) differential thermal analysis (DTA) of PZT spin coating solution and PZT ink. The inset of the TGA curve represents the normalized residual mass $(\triangle N R M=$ $\left(m-m_{\text {final }}\right) /\left(100-m_{\text {final }}\right)$, with $m$ and $m_{\text {final }}$ expressed in \%, where $m_{\text {final }}$ is the mass at $500{ }^{\circ} \mathrm{C}$ ) in the $250-500{ }^{\circ} \mathrm{C}$ temperature range. The highlighted temperature ranges denote the temperatures used in the deposition process.

system cannot be excluded and could account for the absence of three distinct evaporation events.

A slight loss of mass is then recorded until $500{ }^{\circ} \mathrm{C}$ for both PZT precursor solutions. The broad exothermic contribution in this range can be associated to pyrolysis (decomposition of the remaining organics) and crystallization events. The inset of Fig. 2a shows mass variation in the $250-500{ }^{\circ} \mathrm{C}$ temperature range normalized with respect to the final residual mass $(\triangle \mathrm{NRM})$.
From that representation, it is clear that the proportion of organic residual content in the PZT ink is always higher than that of the spin coating solution up to $500{ }^{\circ} \mathrm{C}$.

Note that the thermal analysis was carried out with a constant temperature ramp of $10{ }^{\circ} \mathrm{C} \mathrm{min}{ }^{-1}$. The actual heat ramps experienced by samples under typical processing conditions are much higher due to the use of hot plates for drying and pyrolysis and rapid thermal annealing (RTA) for crystallization. Nevertheless, this analysis gives a clear hint about the differences in the way organics are eliminated from spin-coated and inkjet-printed PZT thin films. We therefore proceeded with a closer examination of the pyrolysis step in the case of inkjet-printed PZT films.

\subsection{FTIR study of the influence of pyrolysis temperature and time}

The Fourier transform infra-red (FTIR) spectrum of the PZT ink measured in attenuated total reflection (ATR) mode is shown in Fig. 3a. Absorption bands can be associated to the ink solvents, which are the main constituents at that stage (Fig. S5, ESI $\dagger$ ). Characteristic bands corresponding to $\mathrm{O}-\mathrm{H}$ and $\mathrm{C}-\mathrm{H}$ stretching are found in the $3000-3600 \mathrm{~cm}^{-1}$ and $2800-3000 \mathrm{~cm}^{-1}$ ranges, respectively. In the fingerprint region of the spectrum, the strongest absorption bands in the $1000-1100 \mathrm{~cm}^{-1}$ range can be ascribed to aliphatic alcohol and ether moieties.

In order to study the chemical transformations of the film from its wet state after printing to the crystallized form, we used FTIR spectroscopy in grazing angle mode (see Experimental), Fig. 3a. The chemical signature of the ink is mostly preserved in the dried film $\left(175{ }^{\circ} \mathrm{C}\right.$ for $\left.1 \mathrm{~min}\right)$, strongly suggesting the presence of residual glycerol and probably ethylene glycol. FTIR spectra for two pyrolysis conditions are shown in Fig. 3a, namely $350{ }^{\circ} \mathrm{C}$ for $0.5 \mathrm{~min}$ and $475{ }^{\circ} \mathrm{C}$ for $10 \mathrm{~min}$. Two groups of absorption bands can be identified in the fingerprint region of the spectrum at $1100-1800 \mathrm{~cm}^{-1}$ and $600-800 \mathrm{~cm}^{-1}$. The first one can be attributed to the remaining organics (presumably oxidized carbon species such as carboxylates and carbonates), ${ }^{27}$ 

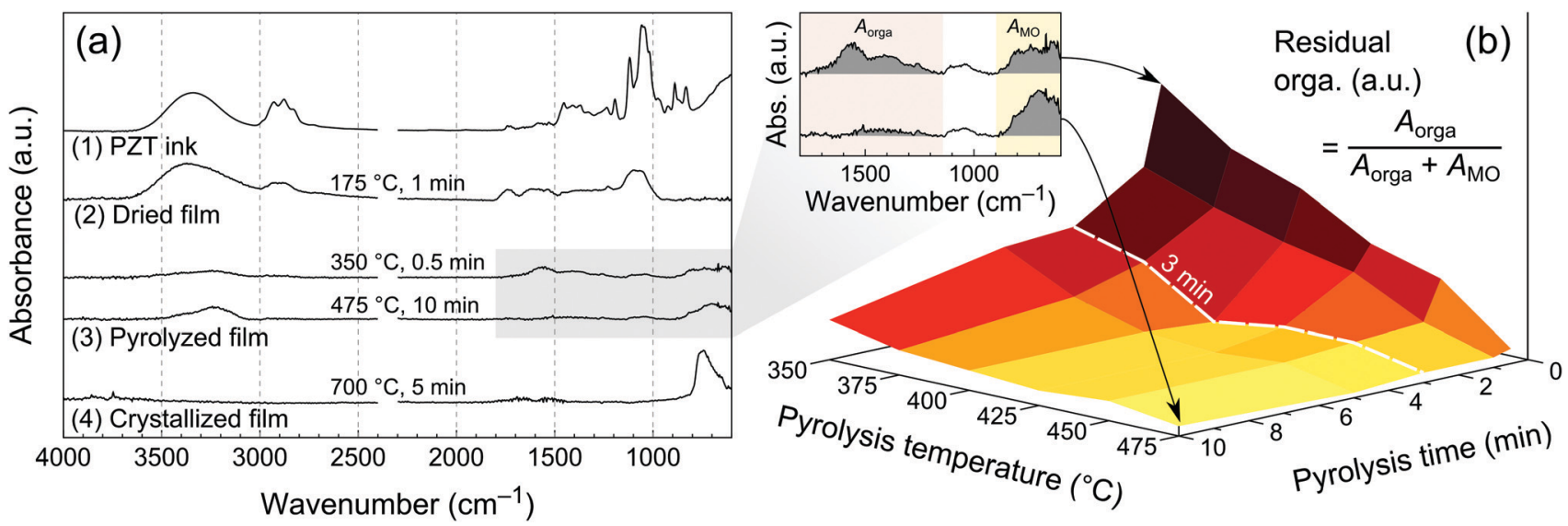

Fig. 3 (a) FTIR spectra illustrating transformations of the PZT ink from liquid to crystallized state: (1) FTIR spectrum of the PZT ink acquired in ATR mode and downscaled for comparison with FTIR spectra acquired in grazing angle mode, namely a single layer printed on platinized silicon and (2) dried at $175{ }^{\circ} \mathrm{C}$ for $1 \mathrm{~min}$, followed by (3) pyrolysis at $350^{\circ} \mathrm{C}$ for $0.5 \mathrm{~min}$ or $475^{\circ} \mathrm{C}$ for $10 \mathrm{~min}$ and finally after (4) crystallization at $700{ }^{\circ} \mathrm{C}$ for 5 min. (b) The region of interest between 600 and $1800 \mathrm{~cm}^{-1}$ in the FTIR spectra of pyrolyzed films was used to draw the correlation between pyrolysis temperature and time and amount of residual organics.

while the second to metal-oxygen bonds. ${ }^{28}$ The latter absorption band becomes more intense and sharper in the crystallized layer (suggesting transformation from amorphous to crystalline state), while the one attributed to organics vanishes, as can be expected from the TGA data.

In order to study the influence of pyrolysis temperature and time on the amount of residual organics in the pyrolyzed films, we fabricated a series of samples by printing a single layer of PZT ink, drying at $175{ }^{\circ} \mathrm{C}$ for $1 \mathrm{~min}$, then we pyrolyzed them between 350 and $475{ }^{\circ} \mathrm{C}$ for a period ranging from $0.5 \mathrm{~min}$ to $10 \mathrm{~min}$. FTIR spectra were then recorded and processed. The amount of residual organics was associated with the relative integrated intensity of absorption bands in the $1100-1800 \mathrm{~cm}^{-1}$ region of the FTIR spectra, according to eqn (2).

$$
\text { Residual organics (a.u.) }=\frac{A_{\text {orga }}}{A_{\text {orga }}+A_{\mathrm{MO}}}
$$

The results are shown in Fig. 3b, where this ratio was plotted as a $3 \mathrm{D}$ surface. In this landscape representation, the elevated areas correspond to high residual organics, while the bottom flat area is associated with low organic content. The boundaries of the latter are $T_{\text {pyro }} \geq 400{ }^{\circ} \mathrm{C}$ and $t_{\text {pyro }} \geq 3 \mathrm{~min}$, and indicate the minimal pyrolysis parameters required to achieve the lowest organic content. Interestingly, it appears that extending the pyrolysis time to $10 \mathrm{~min}$ at $350{ }^{\circ} \mathrm{C}$ or $375{ }^{\circ} \mathrm{C}$ still results in a residual organic content, which sets the requirement for $T_{\text {pyro }} \geq 400{ }^{\circ} \mathrm{C}$. These results also provide a qualitative indication of the pyrolysis kinetics as a function of temperature. For temperatures lower than $450{ }^{\circ} \mathrm{C}$, pyrolysis only tends towards completion after $3 \mathrm{~min}$, as a significant organic residue is still present after $0.5 \mathrm{~min}$ and $1 \mathrm{~min}$ of pyrolysis.

\subsection{Microstructural characterization}

The FTIR study was carried out for very thin layers $(<20 \mathrm{~nm})$ resulting from a single deposition. Thicker films are required in order to assess their quality in terms of morphology and functional properties. We therefore went on to study the microstructure of $200 \mathrm{~nm}$-thick films (12 depositions) pyrolyzed at different temperatures along the 3 min line (path drawn in Fig. 3b), as it allowed for reasonable processing durations.

Scanning electron microscopy (SEM) cross sections of the PZT thin films crystallized at $700{ }^{\circ} \mathrm{C}$ are presented in Fig. 4a. Porosity is present in the films pyrolyzed at $350{ }^{\circ} \mathrm{C}$ and $375{ }^{\circ} \mathrm{C}$, whereas the films pyrolyzed at $400{ }^{\circ} \mathrm{C}$ and higher temperatures are comparatively denser. The density was also assessed by X-ray reflectivity (XRR) measurements (Fig. S6, ESI $\dagger$ ). The inset of Fig. 4b shows the improvement of density with pyrolysis temperature. The extracted densities were normalized to the densities for the lowest pyrolysis temperatures and expressed as a percentage variation $\left(\Delta \rho_{\text {norm }}\right)$. It can be seen that above a threshold between 400 and $425{ }^{\circ} \mathrm{C}$, density improves by about $9 \%$.

This observation can be linked with the previous study (Fig. 3b), inferring a strong correlation between porosity and the presence of residual organics in the layers after pyrolysis. In that case, the elimination of organics occurs during the crystallization stage. The rapid evolution of gaseous decomposition products as a result of fast heating rate $\left(50{ }^{\circ} \mathrm{C} \mathrm{s}^{-1}\right)$ and high crystallization temperature $\left(700{ }^{\circ} \mathrm{C}\right)$ hinders film densification, ${ }^{29}$ resulting in a granular microstructure with substantial intergranular porosity, which is also visible in SEM surface micrographs shown in Fig. S7 (ESI $\dagger$ ). Comparison of SEM cross sections of the films after pyrolysis and crystallization (Fig. S8, ESI $\dagger$ ) confirms that large pores develop during crystallization, in particular at the PZT/platinum interface. In contrast, the crystallization of printed PZT films with minimal residual organics after pyrolysis gives rise to dense columnar microstructure.

X-ray diffraction (XRD) patterns recorded in $\theta-2 \theta$ geometry show that all the printed PZT films are crystallized in the perovskite phase (Fig. 4b). Films pyrolyzed at $350{ }^{\circ} \mathrm{C}$ exhibit random orientation. Interestingly, significant $\{100\}$ orientation is detected in the films pyrolyzed at $375^{\circ} \mathrm{C}$. However, for pyrolysis temperatures equal to and higher than $400{ }^{\circ} \mathrm{C}$, the $\{111\}$ texture 

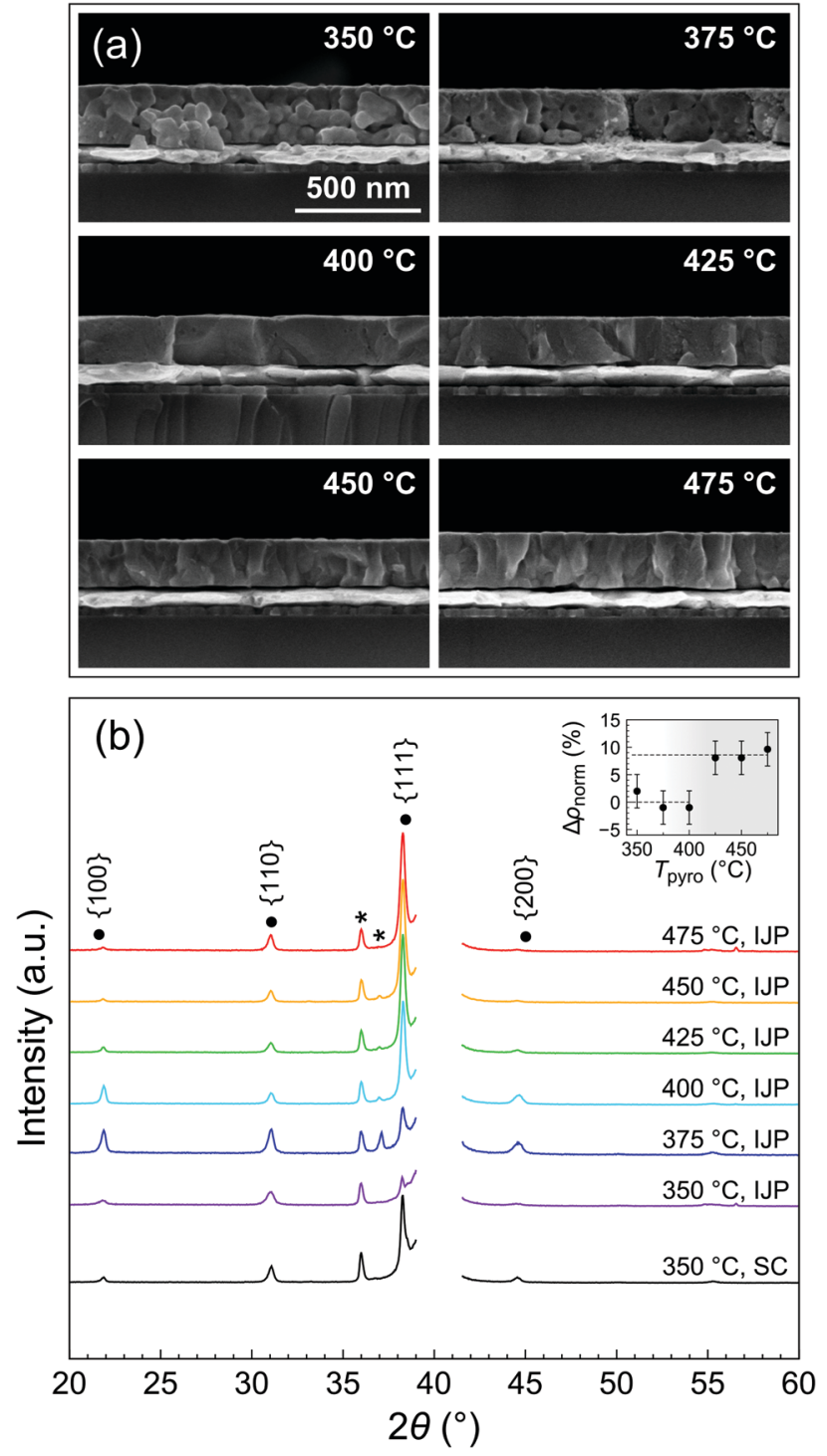

Fig. 4 (a) SEM cross sections and (b) XRD patterns of crystallized inkjetprinted (IJP) PZT thin films on platinized silicon (12 layers) showing the evolution of texture and microstructure as function of pyrolysis temperature for a pyrolysis time of $3 \mathrm{~min}$ (corresponds to the path represented in Fig. 3b). Crystallization was performed at $700{ }^{\circ} \mathrm{C}$. The XRD pattern of a spin-coated (SC) PZT film grown on platinized silicon is shown for comparison. Peaks marked with an asterisk are due to the substrate. The $\mathrm{Pt}(111)$ peak is masked for clarity. The inset of (b) shows the improvement of normalized relative density $\left(\rho_{\text {norm }}\right)$ extracted from XRR measurements.

becomes predominant. PZT films grown on unseeded platinized silicon may adopt the texture of the underlying $\mathrm{Pt}(111)$ electrode in some cases. ${ }^{30}$ Furthermore, it is known that the development of $\{111\}$ texture can be associated with the appearance of a transient intermetallic $\mathrm{Pt}_{x} \mathrm{~Pb}$ at the interface, formed as a result of reduction of $\mathrm{Pb}$ (II) to $\mathrm{Pb}(0)$ in the presence of remaining organics (reducing environment) and diffusion into the Pt electrode. In the case of the PZT films pyrolyzed at $350{ }^{\circ} \mathrm{C}$, it is probable that the crystallization proceeds via homogeneous nucleation due to the concomitant evolution of gases, disrupting substrate-templated growth and resulting in random orientation. This effect is less pronounced for the film pyrolyzed at $375{ }^{\circ} \mathrm{C}$, where some degree of $\{100\}$ and $\{111\}$ texture is observed. For the sake of comparison, we also show in Fig. $4 \mathrm{~b}$ the XRD pattern of a spin-coated PZT film, which was deposited on pristine platinized silicon (without a seed layer). This film was dried at $130{ }^{\circ} \mathrm{C}$ for $3 \mathrm{~min}$, pyrolyzed at $350{ }^{\circ} \mathrm{C}$ for $3 \mathrm{~min}$ and crystallized at $700{ }^{\circ} \mathrm{C}$ for $5 \mathrm{~min}$. A significant degree of $\{111\}$ texture can be detected, similarly to what is observed for the inkjet-printed films pyrolyzed at $T \geq 400{ }^{\circ} \mathrm{C}$.

\subsection{Electromechanical characterization}

Polarization-electric field $(P-E)$ loops for the series of PZT films is presented in Fig. 5a. A typical ferroelectric response could be measured for all the samples. The porous samples pyrolyzed at 350 and $375{ }^{\circ} \mathrm{C}$ exhibit the lowest remanent polarization, with $P_{\mathrm{r}}=8.0$ and $10.2 \mu \mathrm{C} \mathrm{cm}^{-2}$, respectively. Both remanent polarization $\left(P_{\mathrm{r}}\right)$ and maximum polarization $\left(P_{\max }\right)$ increase with increasing pyrolysis temperature (see inset of Fig. 5a), while the coercive field remains practically unchanged throughout the series $\left(E_{\mathrm{c}} \sim\right.$ $60 \mathrm{kV} \mathrm{cm}^{-1}$ ). Note that some dependence of the coercive field on porosity could be expected. However, the relationship between coercive field and porosity is not trivial and often nonlinear, as it can be influenced by the level of porosity and its distribution in the film. ${ }^{31,32}$ PZT films pyrolyzed at the highest temperature $\left(475{ }^{\circ} \mathrm{C}\right)$ display a remanent polarization of $23.7 \mu \mathrm{C} \mathrm{cm}^{-2}$.
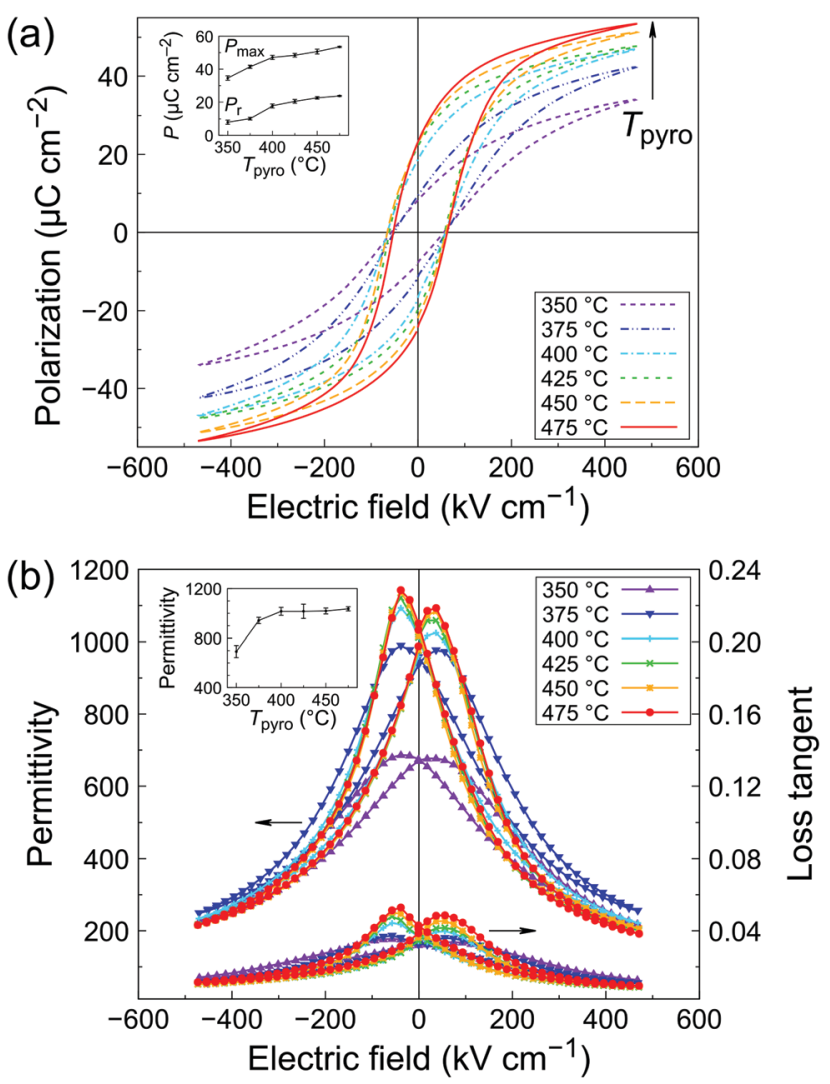

Fig. 5 (a) Polarization-electric field at $100 \mathrm{~Hz}$ and (b) permittivity-electric field loops at $1 \mathrm{kHz}\left(V_{\mathrm{AC}}=100 \mathrm{mV}\right)$ measured for inkjet-printed $200 \mathrm{~nm}$ thick PZT films as function of the pyrolysis temperature $T_{\text {pyro }}$ (pyrolysis time $t_{\text {pyro }}=3 \mathrm{~min}$ ). 
(a)
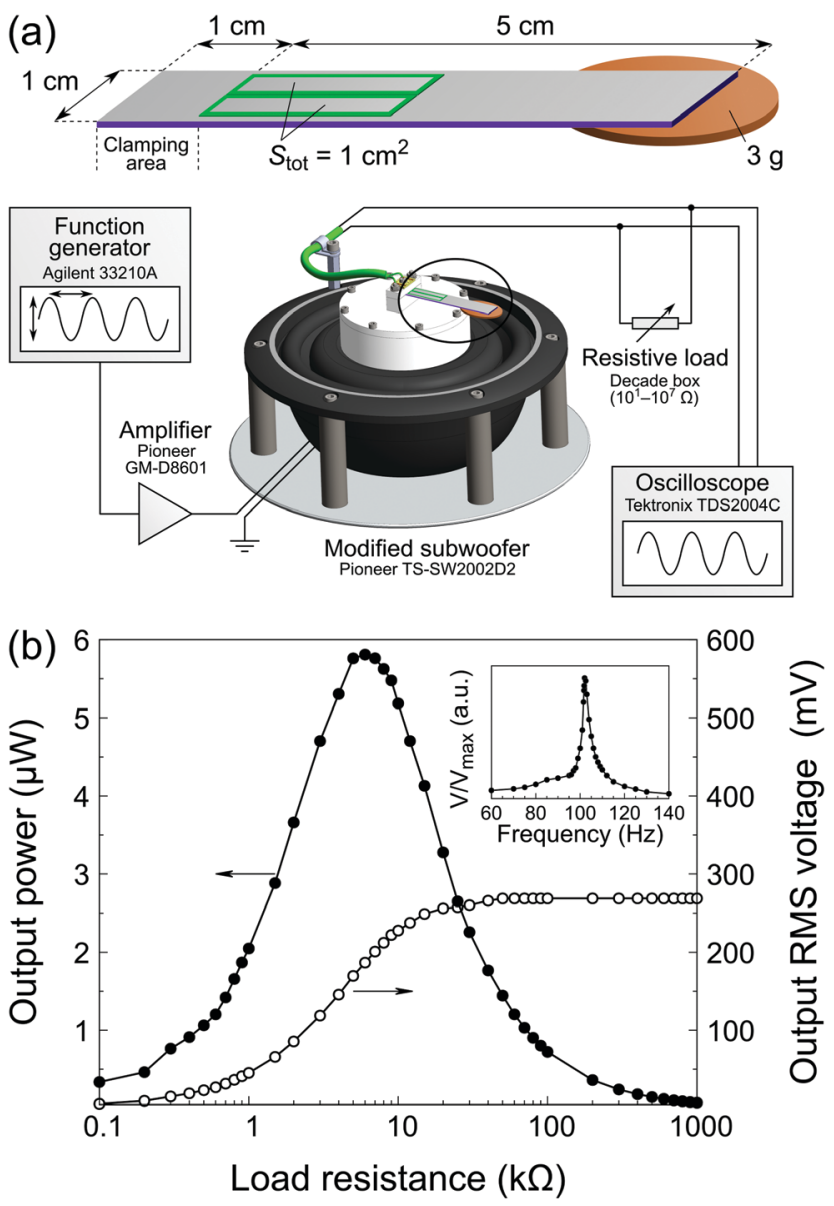

Fig. 6 (a) Description of the energy harvester based on inkjet-printed PZT films. (b) Energy harvester output power and voltage as function of load resistance. The inset shows normalized output voltage as function of frequency. Resonance of the cantilever beam occurs at $102 \mathrm{~Hz}$.

Permittivity-electric field $(\varepsilon-E)$ characteristics are shown in Fig. 5b. As seen in the inset, permittivity at zero bias increases with increasing pyrolysis temperature until $400{ }^{\circ} \mathrm{C}$, after which a plateau is observed $\left(\varepsilon^{\prime} \sim 1000\right.$, see inset of Fig. $\left.5 b\right)$. Dielectric losses also slightly increase with increasing pyrolysis temperature, from 0.034 to 0.042 . This behavior is typical of ferroelectric thin films and mainly comes form extrinsic contributions (domain walls). ${ }^{33}$ At high bias fields, films pyrolyzed at 350 and $375{ }^{\circ} \mathrm{C}$ exhibit a higher loss tangent than the rest of the series. This could be ascribed to the higher leakage current at high fields in the $P-E$ measurements, as shown in Fig. S9 (ESI $\dagger$ ). A higher amount of defects in the porous films could explain this trend. Films pyrolyzed at $T \geq 400{ }^{\circ} \mathrm{C}$ display the best electrical properties, which correlates well with the observed densification and columnar microstructure of the films. The results are compiled in Table $\mathrm{S10}$ (ESI $\dagger$ ) and compared with the literature. The electrical properties of our inkjet-printed PZT films are in line with state-of-the-art solution-derived films.

In order to test the functionality of our inkjet-printed PZT films, we implemented them in a simple unimorph energy harvester (EH) illustrated in Fig. 6a. The printing process described herein $\left(T_{\text {pyro }}=425{ }^{\circ} \mathrm{C}\right)$ was performed five times, yielding a final PZT thickness of $1 \mu \mathrm{m}$. After poling, the device was mounted on a shaker. The resonance curve and power versus load resistance curves are shown in Fig. 6b. The device resonant frequency is $102 \mathrm{~Hz}$, in good agreement with the theoretical value predicted by the Euler-Bernoulli beam model (see Fig. S11, ESI $\dagger$ ). The maximum output power at resonance is $5.8 \mu \mathrm{W}$ for a $6 \mathrm{k} \Omega$ resistive load. In addition, the device was tested for an extended period of time to assess aging. No degradation of the properties was observed after $25 \times 10^{6}$ cycles, as seen in Fig. S12 (ESI $\dagger$ ). Considering that the active material volume for a single device is $0.1 \mathrm{~mm}^{3}$, we report a power density of $58 \mu \mathrm{W} \mathrm{mm} \mathrm{m}^{-3}$, which is comparable to devices previously described in the literature, ${ }^{38}$ as shown in Table 2 . In these examples, PZT was deposited either via spin coating ${ }^{35}$ or rf-magnetron sputtering, ${ }^{36,37}$ whereas our work features fully inkjet-printed piezoelectric layers.

We estimate that growing $0.1 \mathrm{~mm}^{3}$ of PZT for a single $\mathrm{EH}$ device via our inkjet printing process only requires $\sim 20 \mu \mathrm{L}$ of ink. Even with purging and priming operations, the total ink consumption to fabricate a single device is well below $1 \mathrm{~mL}$, making this process remarkably cost-efficient compared to conventional spin coating deposition. These promising results provide a solid basis for further developments, such as improving process time-efficiency by reducing the number of processing steps (i.e. printing thicker layers via tailoring of the ink formulation and printing strategy) and controlling the texture of the printed layers.

Table 2 Comparison of energy harvester characteristics with similar works from the literature

\begin{tabular}{|c|c|c|c|c|}
\hline Ref. & Fang et al..$^{34}$ & Morimoto et al. ${ }^{35,36}$ & Yeo et $a l_{.}^{37}$ & This work \\
\hline Year & 2006 & 2010 & 2016 & 2019 \\
\hline Process & Spin coating & Sputtering & Sputtering & Inkjet printing \\
\hline Thickness ( $\mu \mathrm{m})$ & 1.64 & 2.8 & 3 (bimorph) & 1 \\
\hline Texture & - & $(001)$ & $(001)$ & $\{111\}$ \\
\hline$P_{\mathrm{r}}\left(\mu \mathrm{C} \mathrm{cm}{ }^{-2}\right)$ & 14 & 30 & 40 & 20 \\
\hline$E_{\mathrm{c}}\left(\mathrm{kV} \mathrm{cm}^{-1}\right)$ & 30 & 50 & 65 & 48 \\
\hline$\varepsilon^{\prime}$ & - & 166 & 210 & 1200 \\
\hline $\tan \delta$ & - & - & 0.03 & 0.05 \\
\hline Power $(\mu \mathrm{W})$ & 2.2 & 5.3 & 149 & 5.8 \\
\hline Frequency (Hz) & 609 & 126 & 6 & 102 \\
\hline Acceleration $\left(\mathrm{m} \mathrm{s}^{-2}\right)$ & 10 & 5 & 1 & 50 \\
\hline Active volume $\left(\mathrm{mm}^{3}\right)$ & 0.78 & 0.26 & 1.2 & 0.1 \\
\hline Power density $\left(\mu \mathrm{W} \mathrm{mm}^{-3}\right)$ & 7.6 & 21 & 124 & 58 \\
\hline
\end{tabular}




\section{Conclusions}

In this study, we present the development of a precursor ink for lead zirconate titanate (PZT) thin films from a conventional precursor solution modified with high-boiling-point co-solvents. The presence of the latter in the solution was shown to modulate processing conditions. In particular, FTIR analysis of pyrolyzed films revealed that the elimination of residual organics in the layers could be achieved by pyrolysis for $3 \mathrm{~min}$ at $T \geq 400{ }^{\circ} \mathrm{C}$. This observation was correlated with porosity in the final crystallized layers, as well as electrical properties. Dense, $200 \mathrm{~nm}$-thick $\{111\}$ textured films with $P_{\mathrm{r}}=23 \mu \mathrm{C} \mathrm{cm}^{-2}, E_{\mathrm{c}}=60 \mathrm{kV} \mathrm{cm}^{-1}, \varepsilon^{\prime}=1000$ and $\tan \delta=0.04$ were fabricated by inkjet printing. Finally, we implemented the printed piezoelectric layers in a simple energy harvesting device, which provided a $5.8 \mu \mathrm{W}$ power output at $6 \mathrm{k} \Omega$, thus demonstrating the potential of inkjet printing technology for the fabrication of low-cost electromechanical transducers.

\section{Conflicts of interest}

There are no conflicts to declare.

\section{Acknowledgements}

The authors acknowledge financial support from the Luxembourgish National Research Fund (FNR) under projects CO-FERMAT (FNR/P12/4853155/Kreisel), TRAPIZT (C-PPP-17/MS/11814049/TRAPIZT/Defay) and HARVESTORE (FNR/INTER/ANR/18/12618689/ Defay). The authors also wish to thank Benoît Marcolini and Régis Vaudemont for performing thermal analyses, Jean-Baptiste Chemin for the deposition of platinum top electrodes, Maryline Moreno for the measurement of FTIR spectra and Mathieu Gérard for the development of the test bench for energy harvesting.

\section{Notes and references}

1 P.-H. Cazorla, O. Fuchs, M. Cochet, S. Maubert, G. Le Rhun, Y. Fouillet and E. Defay, Sens. Actuators, A, 2016, 250, 35-39.

2 F. Filhol, E. Defaÿ, C. Divoux, C. Zinck and M.-T. Delaye, Sens. Actuators, A, 2005, 123-124, 483-489.

3 S.-G. Kim, S. Priya and I. Kanno, MRS Bull., 2012, 37, 1039-1050.

4 S. Roundy and P. K. Wright, Smart Mater. Struct., 2004, 13, 1131-1142.

5 P. Muralt, J. Micromech. Microeng., 2000, 10, 136-146.

6 G. L. Brennecka, J. F. Ihlefeld, J.-P. Maria, B. A. Tuttle and P. G. Clem, J. Am. Ceram. Soc., 2010, 93, 3935-3954.

7 N. Bassiri-Gharb, Y. Bastani and A. Bernal, Chem. Soc. Rev., 2014, 43, 2125-2140.

8 B. Derby, Annu. Rev. Mater. Res., 2010, 40, 395-414.

9 J. Windle and B. Derby, J. Mater. Sci. Lett., 1999, 18, 87-90.

10 T. Wang and B. Derby, J. Am. Ceram. Soc., 2005, 88, 2053-2058.

11 D. Kuscer, O. Noshchenko, H. Uršič and B. Malič, J. Am. Ceram. Soc., 2013, 96, 2714-2717.
12 T. Bakarič, B. Malič and D. Kuscer, J. Eur. Ceram. Soc., 2016, 36, 4031-4037.

13 S. P. Bathurst, H. W. Lee and S. G. Kim, 2008 IEEE 21st International Conference on Micro Electro Mechanical Systems, 2008, pp. 391-394.

14 O. Machida, A. Shimofuku, R. Tashiro, A. Takeuchi, Y. Akiyama and E. Ohta, Jpn. J. Appl. Phys., 2012, 51, 09LA11.

15 N. Godard, S. Glinšek, A. Matavž, V. Bobnar and E. Defay, Adv. Mater. Technol., 2019, 4, 1800168.

16 A. Matavž, A. Benčan, J. Kovač, C.-C. Chung, J. L. Jones, S. Trolier-McKinstry, B. Malič and V. Bobnar, ACS Appl. Mater. Interfaces, 2019, 11, 45155-45160.

17 D. Jang, D. Kim and J. Moon, Langmuir, 2009, 25, 2629-2635.

18 R. D. Deegan, O. Bakajin, T. F. Dupont, G. Huber, S. R. Nagel and T. A. Witten, Nature, 1997, 389, 827-829.

19 E. Tekin, B.-J. de Gans and U. S. Schubert, J. Mater. Chem., 2004, 14, 2627-2632.

20 A. Matavž, R. C. Frunza, A. Drnovšek, V. Bobnar and B. Malič, J. Mater. Chem. C, 2016, 4, 5634-5641.

21 A. Matavž, V. Bobnar and B. Malič, Langmuir, 2017, 33, 11893-11900.

22 C. W. Sele, T. von Werne, R. H. Friend and H. Sirringhaus, Adv. Mater., 2005, 17, 997-1001.

23 I. Bretos, R. Jiménez, J. Ricote and M. L. Calzada, Chem. Soc. Rev., 2018, 47, 291-308.

24 M.-G. Kim, M. G. Kanatzidis, A. Facchetti and T. J. Marks, Nat. Mater., 2011, 10, 382-388.

25 J. D. Berry, M. J. Neeson, R. R. Dagastine, D. Y. Chan and R. F. Tabor, J. Colloid Interface Sci., 2015, 454, 226-237.

26 B. Dou, V. Dupont, P. T. Williams, H. Chen and Y. Ding, Bioresour. Technol., 2009, 100, 2613-2620.

27 R. M. Silverstein, F. X. Webster, D. J. Kiemle and D. L. Bryce, Spectrometric Identification of Organic Compounds, John Wiley \& Sons, Inc., Hoboken, NJ, 8th edn, 2014.

28 Y. Wang and J. J. Santiago-Avilés, Nanotechnology, 2004, 15, 32-36.

29 Y. Bastani and N. Bassiri-Gharb, J. Am. Ceram. Soc., 2012, 95, 1269-1275.

30 S. Trolier-McKinstry and P. Muralt, J. Electroceram., 2004, 12, 7-17.

31 V. Stancu, M. Lisca, I. Boerasu, L. Pintilie and M. Kosec, Thin Solid Films, 2007, 515, 6557-6561.

32 Y. Zhang, J. Roscow, R. Lewis, H. Khanbareh, V. Y. Topolov, M. Xie and C. R. Bowen, Acta Mater., 2018, 154, 100-112.

33 A. Tagantsev, V. Sherman, K. Astafiev, J. Venkatesh and N. Setter, J. Electroceram., 2003, 11, 5-66.

34 H. B. Fang, J. Q. Liu, Z. Y. Xu, L. Dong, L. Wang, D. Chen, B. C. Cai and Y. Liu, Microelectron. J., 2006, 37, 1280-1284.

35 K. Morimoto, I. Kanno, K. Wasa and H. Kotera, Sens. Actuators, A, 2010, 163, 428-432.

36 I. Kanno, H. Kotera and K. Wasa, Sens. Actuators, A, 2003, 107, 68-74.

37 H. G. Yeo, X. Ma, C. Rahn and S. Trolier-McKinstry, Adv. Funct. Mater., 2016, 26, 5940-5946.

38 R. Xu and S.-G. Kim, PowerMEMS, 2012, pp. 464-467. 